\title{
A atuação da Discoteca Oneyda Alvarenga na construção do patrimônio imaterial: revendo uma trajetória
}

\section{Ana Paula Silva}

\begin{abstract}
Graduada em Biblioteconomia. Mestre em Ciência da Informação pela Escola de Ciência da Informação da Universidade Federal de Minas Gerais. Doutoranda do Programa de Pósgraduação em Ciência da Informação da ECI/UFMG. Analista de Políticas Públicas da Prefeitura de Belo Horizonte
\end{abstract}

Alcenir Soares dos Reis

Professora Associada da Escola de Ciência da Informação da Universidade Federal de Minas Gerais. Doutora em Educação pela FAE/ UFMG. Mestre em Biblioteconomia pela ECI/UFMG

Este artigo apresenta o histórico, a organização e o significado da Discoteca Oneyda Alvarenga, bem como o trabalho realizado pela instituição, em termos dos processos de construção do patrimônio cultural imaterial, evidenciando a sua originalidade e inovação em acervos musicológicos e etnográficos. A constituição do acervo etnográfico, com gravação em suporte não convencional, resultou das viagens e estudos promovidos pela Missão de Pesquisas Folclóricas e a este se soma outros trabalhos pioneiros no Brasil, que inauguraram os projetos de pesquisa científica dedicados à cultura brasileira. Todos os materiais recolhidos pela Missão foram organizados por Oneyda Alvarenga e encontram-se disponíveis à consulta pública na Discoteca Oneyda Alvarenga, na cidade de São Paulo, no Centro Cultural São Paulo (CCSP). A discussão deste tema, no âmbito da Ciência da Informação, tem como objetivo evidenciar a importância da produção de conhecimento e informação acerca da manutenção e gerenciamento de acervos não convencionais, destacando-se os aspectos referentes ao patrimônio cultural, folclore e acervo audiovisual, com vistas a ampliar a reflexão desta discussão na área.

Palavras-chaves: Patrimônio cultural; Folclore; Acervo audiovisual; Informação. 


\title{
The performance of Disco Oneyda Alvarenga in the construction of intangible heritage: reviewing a trajectory
}

\begin{abstract}
This article presents the historical, organization and meaning of "Discoteca Oneyda Alvarenga", as well as the work of the institution in terms of building processes of incorporeal cultural heritage, showing their originality and innovation in musicological and ethnographic collections. The constitution of the ethnographic collection, in support unconventional recorded, was created as a result of travel and studies sponsored by the Folklore Research Mission and this adds other pioneering work in Brazil, who inaugurated the scientific research projects dedicated to Brazilian culture. All materials collected by the Mission were organized by Oneyda Alvarenga and are available for public consultation at the "Discoteca Oneyda Alvarenga", in the city of São Paulo, at São Paulo exhibition center. The discussion of this matter in the context of Information Science aims to highlight the importance of the production of knowledge and information about the maintenance and management of unconventional collections, highlighting aspects related to cultural heritage, folklore and audiovisual collection in order to enlarge the reflection of this discussion in the area.
\end{abstract}

Keywords: Cultural heritage; Folklore; Audiovisual collection; Information

Recebido em 21.06.2013 Aceito em 11.11.2013

\section{Introdução}

Este artigo visa a apresentar parte da pesquisa que se encontra em curso, no nível de doutorado, cuja centralidade é o estudo e a apreensão do processo de construção do patrimônio cultural no Brasil, em especial o patrimônio imaterial. Durante o processo de levantamento e estudo da bibliografia concernente à referida temática, identificamos a instituição "Discoteca Oneyda Alvarenga" - objeto da pesquisa - criada por Mário de Andrade, em 1935, época em que era Diretor do Departamento de Cultura de São Paulo, órgão que se orientava para a implantação e manutenção de diversas instituições de estudo, pesquisa e promoção de serviços culturais. 
É notório, no que se refere aos estudos sobre a construção do patrimônio cultural brasileiro, o papel fundamental de Mário de Andrade, destacando que ele, como poucos em sua época, colaborou para fixar as bases teóricas, ideológicas e políticas para a formulação de uma legislação de preservação do patrimônio cultural - material e imaterial - no Brasil.

No que se refere à preservação das manifestações da cultura brasileira e da promoção da cientifização do saber cultural, o conhecimento de Mário de Andrade também foi de importância decisiva. Seu trabalho, nesta área, deriva de suas investigações e projetos, no sentido de apreender e identificar a autêntica cultura nacional, permitindo-Ihe avançar para além do projeto modernista, movimento do qual o escritor foi articulador e militante. Segundo Moya,

[...] Mário e os intelectuais ligados ao Departamento de Cultura de São Paulo, buscavam nas formas tradicionais da cultura popular (distinguindo esta da influência estrangeira) uma identidade paulista e brasileira que colocaria o Brasil no caminho da modernidade. Assim "procuraram conhecer a cidade e até mesmo o país" para organizar "todos os campos da atividade cultural". No âmbito musical, a instituição que cuidaria disso seria a Discoteca Pública Municipal, órgão criado dentro do Departamento de Cultura por Mário de Andrade (MOYA, 2010, p. 34).

Em face dos aspectos anteriormente indicados, elegemos como objeto de estudo a Discoteca Pública Municipal, que representou a tentativa prática da criação - através da educação musical de compositores e ouvintes e a partir da pesquisa de material folclórico e fonético, que a instituição cuidou de recolher e preparar para consultas de uma música verdadeiramente nacional.

O nome da discoteca foi alterado de Discoteca Pública Municipal (DPM) para Discoteca Oneyda Alvarenga (DOA), em homenagem a sua primeira diretora Oneyda Alvarenga, musicista, musicóloga, poeta e discotecária. Foi discípula de Mário de Andrade e desde o momento em que o olhar modernista fixou-se sobre a cultura nacional, vemos na figura da homenageada um exemplo de ação e reflexão sobre as possibilidades de construção de acervos específicos, voltados à proteção material e imaterial da cultura popular.

Ao longo deste artigo, pretende-se explicitar o processo que tornou possível, na DPM, garantir o acesso aos bens culturais vinculados aos processos de preservação e informação, temas que são de importância e interesse a todas as áreas relativas ao patrimônio cultural, seja no Brasil ou no exterior.

Em razão da importância e significado da discoteca municipal, revelado pela literatura, constituiu-se como objeto da pesquisa compreender sua criação, que inova, no Brasil, a construção de acervos etnográficos em suporte magnético, além de criar um espaço para a 
consulta de áudio e imagem, possibilitando a pesquisa em suporte audiovisual, bem como a utilização do uso da imagem (fotografia e cinema) como suporte metodológico na pesquisa etnográfica. A utilização da imagem fundamentaria a materialização de um patrimônio imaterial: tradições, gestos, músicas, danças, sons e falas, podendo ser capturados, vistos e entendidos, enquanto testemunhos dos sujeitos e/ou comunidades observadas.

Tendo em vista a pertinência do tema no campo da Ciência da Informação, articula-se este texto, tendo como ênfase o trabalho de investigação em termos da atuação e possibilidades da informação no espaço do patrimônio cultural, em especial o patrimônio imaterial. Para fazê-lo, o texto se estrutura de acordo com os seguintes tópicos:

a) Patrimônio cultural e Ciência da informação;

b) Mário de Andrade, Oneyda Alvarenga e a coleção da Missão de Estudos Folclóricos;

c) Discoteca Pública Municipal.

\section{Patrimônio cultural e Ciência da Informaçã}

A Ciência da Informação, como ciência social aplicada, coloca-se como um espaço de geração de conhecimento e tem como centralidade a informação, constituindo-se como objeto de análise, quantificação e mensuração, em termos das diversas aplicações do saber humano. Seu desenvolvimento se dá como resultado das transformações sociais no âmbito da sociedade, bem como da inclusão das tecnologias decorrentes dos estudos e inovações da área da informática, a partir da década de 1950, associada aos conceitos advindos das áreas da documentação e da biblioteconomia.

Três fatos podem ser considerados como responsáveis e necessários à formação da Ciência da Informação: a explosão da informação, a implosão do tempo e a tecnologia. Na realidade, pode-se afirmar que, a partir do advento da informática, foi possível o armazenamento e a mais ampla distribuição de enormes volumes de informação.

No que se refere à produção científica, tal fato pode ser comprovado pelo crescimento da literatura científica, originando grandes bancos de dados e sistemas de recuperação da informação, determinantes para que os teóricos e os profissionais da informação voltassem seus estudos para soluções demandadas por esse crescente e rápido fluxo informacional. Por outro lado, isso teve como consequência a rápida velocidade na transmissão das informações, o que também se reflete em um novo modo de produção, em que a distância foi compensada pela economia de tempo, fator indispensável à organização de diferentes esferas sociais.

Esses elementos são inerentes à concepção da sociedade da informação, definida, assim, por ser uma sociedade que possui a informação como elemento primordial em seus processos de formação social. No campo científico, a Ciência da Informação surge como 
consequência desse momento histórico, que se traduz na formulação a seguir:

[...] tais mudanças provocaram simultaneamente uma mudança epistemológica. Isso nos faz constatar que, hoje, o objeto da Ciência da Informação não é mais o mesmo da biblioteconomia e de suas veneráveis disciplinas co-irmãs. Não é mais a biblioteca e o livro, o centro de documentação e o documento, o museu e o objeto, mas a informação (LE COADIC, 1996, p. 21).

Além da interface que mantém com essas três áreas (documentação, biblioteconomia e arquivologia), a Ciência da Informação ainda possui estreita relação com os campos da Ciência da Computação, da Comunicação, das Ciências Cognitivas e outras afins; tal realidade demonstra uma das características essenciais da Ciência da Informação, que é sua natureza interdisciplinar.

A Ciência da Informação insere-se no campo das Ciências Sociais, pois possui a preocupação de esclarecer seu objeto, a informação, em uma realidade social concreta, voltada para o ser social que procura a informação como mecanismo de interação social e/ou como artefato para a construção de serviços de informação. O conceito desenvolvido por Saracevic (1996) reafirma seu enfoque contemporâneo:

A Ciência da Informação é um campo dedicado às questões científicas e à prática profissional voltadas para os problemas da efetiva comunicação do conhecimento e de seus registros entre os seres humanos, no contexto social, institucional ou individual do uso e das necessidades de informação. No tratamento destas questões são consideradas de particular interesse as vantagens das modernas tecnologias informacionais (SARACEVIC, 1996, p. 47).

Considerando o contexto histórico da Ciência da informação e de suas dimensões teóricas e conceituais, a linha de estudos informação, cultura e sociedade, área de concentração em que se insere a pesquisa, tem como escopo de investigação

[...] a informação enquanto fenômeno social, apreendendo-a a partir de seus domínios epistemológicos e contextos sociais. São contemplados estudos e pesquisas que abrangem as inter-relações da informação com as esferas do Estado, da sociedade civil e da cultura, e seus desdobramentos nas sociedades contemporâneas (REIS, 2007, p. 23).

Vale destacar, com relação ao patrimônio cultural, que este se constitui, antes de tudo, como um conjunto de saberes, de ações e de 
registros. Ou seja, é, antes de tudo, objeto de transmissão às gerações atuais e futuras de informações, sentidos e valores, fundamentais para a construção de identidades coletivas e para a fruição estética.

Em relação ao patrimônio cultural, sua característica, como todos os outros relativos à produção social, está imbuída de contradições, limites e disputas de poder, estando presente o caráter polissêmico dos termos informação e patrimônio, cercando-os de ambiguidades.

O tema do patrimônio cultural vem alcançando, na literatura da Ciência da Informação, destaque progressivo no cenário nacional e internacional e as discussões a respeito do papel da informação estão presentes nas políticas de proteção ao patrimônio, que incluem desde a legislação acerca das definições do vasto acervo que forma o patrimônio cultural, até as determinações legais sobre a atuação dos diversos profissionais nesse espaço.

No contexto atual, evidenciam-se inúmeras iniciativas registradas pela produção técnico-científica da área $e$, também, aquelas de caráter interdisciplinar, ressaltando-se, neste caso, publicações dos campos de Biblioteconomia, Arquivologia, História, Arquitetura e Museologia, que denotam preocupações de órgãos, de instituições e empresas, de comissões, de pessoas e, de modo amplo, da sociedade com a preservação do conhecimento mundial. O trabalho em torno da proteção do patrimônio cultural se diversifica em função da natureza dos objetos e de sua relação junto às sociedades, que os mantêm e os legitimam.

O termo patrimônio originou-se da palavra pater, que significa pai ou paterno. O patrimônio representava, como ainda representa, os bens de herança que são transmitidos aos filhos. Ao longo dos tempos, o significado do termo patrimônio estendeu-se aos bens de determinados grupos sociais, que eram passados para as gerações futuras como forma de transmitir seus conhecimentos e seu poder de dominação.

É compreendido, como patrimônio cultural, um conjunto de bens culturais classificados segundo sua natureza, subdivididos em patrimônio material e imaterial. No patrimônio material, incluem-se acervos arqueológico, paisagístico e etnográfico, histórico, belas artes e das artes aplicadas. Eles estão divididos em bens imóveis, como os núcleos urbanos, sítios arqueológicos e paisagísticos e bens individuais; e móveis, como coleções arqueológicas, acervos museológicos, documentais, bibliográficos, arquivísticos, videográficos, fotográficos e cinematográficos.

Quanto ao patrimônio bibliográfico, este se insere na grande categoria de patrimônio documental, que pode ser entendido como acervos arquivísticos (particulares ou públicos), acervos iconográficos e acervos bibliográficos de instituições públicas e particulares. Estes acervos, constituídos por materiais bibliográficos e não bibliográficos, registram, em última análise, a produção técnico-científica e cultural da humanidade e estão contidos em suportes diversificados e armazenados em ambientes, às vezes inadequados ao acondicionamento ideal.

A concepção de patrimônio associa-se aos meios de manutenção e de pertencimento da sociedade, que detém o direito ao legado histórico refletido nas coleções e acervos. Historicamente, foi na França, a partir da 
Revolução de 1789, que a atuação dos antiquários entrou em declínio, quando o Estado assumiu e passou a centralizar as atividades preservacionistas. A partir desse momento, iniciou-se a proteção legal de bens culturais, permitindo, assim, que se ampliasse a noção de patrimônio histórico, como relíquias herdadas por toda uma geração de pessoas e não mais por grupos sociais isolados. Por conseguinte, os bens culturais estariam disponíveis ao uso e benefício do povo. Acrescenta-se, também, que a conservação baseada nas práticas particulares deu lugar a uma atividade do Estado como protetor dos bens gerais.

Com a Revolução Francesa, os bens culturais adquiriram uma identidade nacional e foram apoiados por uma legislação específica. Pela primeira vez surgiu a função social da preservação do patrimônio:

[...] a efetivação da preservação dos bens culturais só se encontra socialmente definida, ou seja, só aparece como fato social, quando o Estado assume a sua proteção e, através da ordenação jurídica, os institui e delimita oficialmente enquanto bem cultural, regulamentando o seu uso, a finalidade e o caráter desses bens dentro de leis específicas de propriedade, zoneamento, uso e ocupação do solo (FONSECA, 1997, p. 54).

No Brasil, o patrimônio histórico e artístico nacional foi citado pela primeira vez, como objeto de proteção obrigatória pelo poder público, na Constituição de 1934, sendo que cabia à União e aos Estados proteger as belezas naturais e os monumentos de valor histórico ou artístico. Mais tarde, o Decreto-lei no 25 de 30 de novembro de 1937, primeira lei nacional de proteção ao patrimônio no Brasil, oficializou o resguardo dos nossos bens culturais.

Atualmente, o alerta para a perda de inúmeros bens da nação, incluindo o meio ambiente, os costumes, as línguas e as tradições, é feito constantemente através de instituições de todos os níveis e orientações. Segundo Possamai (2000),

O patrimônio hoje é preocupação de um número expressivo de países em todo o mundo, reunindo profissionais de diversas áreas, que compartilham os postulados técnicos e teóricos relacionados a essas tarefas. As discussões sobre o patrimônio abrangem um grande número de aspectos, que vão desde a identificação de um conjunto cada vez mais abrangente de bens culturais - incluindo não apenas monumentos, mas também os bens naturais e etnológicos - até o gerenciamento e sustentabilidade dos patrimônios junto às comunidades locais (POSSAMAI, 2000, p. 16).

Existe, atualmente, uma preocupação no que se refere ao reconhecimento dos cidadãos pelo bem tombado. Em nosso País, muitos ainda relacionam a ação de preservação patrimonial a uma atividade 
meramente acadêmica, pouco relacionada com a luta pela democracia e os direitos de cidadania, o que tem dificultado a divulgação das ações de preservação e a participação mais ativa da população. É urgente o reconhecimento pela sociedade do bem preservado, bem como de uma identificação com esse mesmo bem.

\subsection{Alterações de conceitos e princípios do patrimônio cultural: em evidência o patrimônio imaterial}

Durante a década de 1970, iniciou-se um processo de ampliação do conceito de patrimônio; tal alteração referiu-se à oposição dos sujeitos à concepção tradicional colecionista, perspectiva dominante até então. Tal situação promoveu um novo pensar na definição do que é patrimoniável e se refletiu, sobretudo, na inclusão e guarda de formas e modos de fazer culturais, gerando novos acervos e outras categorias de memória e tradição.

A tendência internacional, moldada por iniciativa de modernização da política cultural, promoveu uma reflexão crítica e uma renovação conceitual no ramo da preservação do patrimônio cultural, que resultou na ampliação da noção de patrimônio e na adoção do conceito de bens culturais, os quais passaram a ser concebidos como elementos importantes para o desenvolvimento autônomo do país/estado/cidade/região/localidade.

No Brasil, a Constituição de 1988 forneceu espaço para a formulação de legislações locais que garantem o acesso e o direito à memória. Houve uma mudança de direcionamento que culminou com a ampliação da noção de patrimônio, garantindo em lei a participação das comunidades no processo de preservação, inclusive com a qualificação de mão de obra e a inauguração de instituições como as "sociedades dos amigos", que atuam como garantidoras de melhores recursos financeiros e de apoio às atividades de proteção ao patrimônio.

Tais medidas, aliadas ao processo de redemocratização, possibilitaram a inclusão de uma maior diversidade cultural nas medidas protetivas, dando ao objeto/documento maior participação popular no efetivo uso social dos espaços de memória. O patrimônio, com uso social, contribuiu para que diferentes movimentos da sociedade passassem a se ocupar da referida questão, identificado como campo propício à formação de novas identidades coletivas.

Estas alterações proporcionaram, no cenário brasileiro, novos princípios e práticas capazes de imprimir um caráter mais dinâmico, de centros de informação, lazer e de educação do público. Acrescentarem-se novas atribuições àquelas já tradicionais de conservação, tratamento e exibição de acervos, incluindo, dentre estas atividades educativas, eventos culturais e de entretenimento (turismo cultural).

Estes espaços de memória tornaram-se, hoje, instrumentos de extensão cultural, desenvolvendo atividades para atender a um público diversificado, estendendo sua atuação para além de suas sedes, chegando a escolas, fábricas e periferias da cidade. Além de oferecer serviços on- 
line, publicações, dentre outros, a questão patrimonial, na atualidade, centra-se na dualidade: memória $x$ acesso, pautada pela ação dessas instituições na sociedade da informação.

Entretanto, diante do exposto, podemos acrescentar que, para que as instituições sejam produtoras de conhecimento, no contexto da sociedade atual, devem utilizar, em seus processos produtivos, ações e orientações capazes de adequar a esta nova realidade.

Nesse sentido, é crucial perguntarmos: quais são os questionamentos que a necessidade de preservação do patrimônio histórico-cultural suscita? Afinal, por que preservar?

No que se refere aos bens culturais imateriais, de acordo com Márcia Sant'Anna (2003, p. 52), a ideia de preservar o patrimônio imaterial não surgiu das práticas preservacionistas da sociedade ocidental, associadas à cultura material, mas nos países do Oriente e do chamado "Terceiro Mundo". Sobre o registro do patrimônio imaterial, a autora afirma: "não é um instrumento de tutela análogo ao tombamento, [...] que pode também ser complementar a este. [...]. O objetivo é manter o registro da memória desses bens culturais e de sua trajetória no tempo, $[\ldots]^{\prime \prime}$.

Portanto, é necessário realizar uma contextualização, a partir de bibliografia especializada, das políticas de patrimônio cultural, em particular, sobre o patrimônio imaterial, elaboradas e implementadas no Brasil. Foi somente a partir da Convenção sobre o Patrimônio Mundial, Cultural e Natural (UNESCO ${ }^{1}$, 1972) que os países do Ocidente começaram a entender a importância de preservar o patrimônio cultural imaterial, mas foram poucos os países que legislaram nessa direção, como a exemplo da França.

No Brasil, os ideais de preservação do patrimônio imaterial remontam ao Anteprojeto do Serviço do Patrimônio Artístico Nacional, de Mário de Andrade, na década de 1930, quando era evidente a preocupação em proteger os saberes e costumes do povo brasileiro.

Do fim dos anos 1950 até o final de 1990, a UNESCO promoveu uma série de convenções, recomendações e cartas, realizando-se, em 1989, a Conferência Geral na qual se adotou a "Recomendação para a salvaguarda da cultura tradicional e popular", único texto jurídico internacional na matéria, em vigor até os dias atuais.

A edição, no Brasil, do Decreto no 3.551 de 4 de agosto de 2000 (BRASIL, 2000), significou uma tentativa de enfrentar, de algum modo, os desafios propostos à salvaguarda deste tipo de patrimônio. Com o objetivo de "implementar política de inventário, registro e salvaguarda desses bens", o decreto presidencial também sugeriu os diferentes domínios que compõem essa dimensão do patrimônio, por meio da criação dos livros de registro, voltados para os saberes, as celebrações, as formas de

\footnotetext{
${ }^{1}$ A Organização das Nações Unidas para a Educação, a Ciência e a Cultura (UNESCO), fundada em 1946, é uma agência especializada do sistema da Organização das Nações Unidas (ONU) que foi originada a partir da 'Liga das Nações'. O Brasil é um Estado-membro desde a criação da UNESCO e participou de todas as conferências culturais promovidas pela Instituição.
} 
expressão e os lugares (INSTITUTO DO PATRIMÔNIO HISTÓRICO E ARTÍSTICO NACIONAL - IPHAN, 2006).

A grande inovação presente nesse decreto, para o trato do patrimônio imaterial, refere-se a sua forma de registro e à relação que este deve manter com a sociedade. Ressalte-se que os Instrumentos de Registro dos bens imateriais não são fechados, normativos e restritivos, mas abertos aos pontos de vista e expectativas dos portadores de tradições culturais específicas, pressupondo a dinâmica própria dessas tradições, sem pretender, portanto, "engessar" suas formas e conteúdos no tempo e no espaço.

Além do Registro, instrumento legal que possibilita a produção de conhecimento sobre o bem cultural, destaca-se o "Inventário Nacional de Referências Culturais" (INRC), uma metodologia de pesquisa desenvolvida pelo IPHAN, cujo objetivo é a identificação e a produção de conhecimento sobre bens culturais de natureza imaterial. Esses instrumentos, como parte do Plano de Ações de Salvaguarda, auxiliam a formulação de políticas públicas na área. O Decreto 3.551, além de instituir o Registro, apresenta a criação de mais quatro livros destinados à proteção do patrimônio cultural brasileiro, conforme indicado a seguir:

Artigo $1^{0}$ - Fica instituído o Registro de Bens Culturais de Natureza Imaterial que constituem patrimônio cultural brasileiro.

$\S 1^{\circ}$ Esse registro se fará em um dos seguintes livros:

I - Livro de Registro dos Saberes, onde serão inscritos conhecimentos e modos de fazer enraizados no cotidiano das comunidades;

II - Livro de Registro das Celebrações, onde serão inscritos rituais e festas que marcam a vivência coletiva do trabalho, da religiosidade, do entretenimento e de outras práticas da vida social;

III - Livro de Registro das Formas de Expressão, onde serão inscritas manifestações literárias, musicais, plásticas, cênicas e lúdicas;

IV - Livro de Registro dos Lugares, onde serão inscritos mercados, feiras, santuários, praças e demais espaços onde se concentram e reproduzem práticas culturais coletivas (BRASIL, 2000).

Vale notar que, em um dos parágrafos do seu artigo primeiro, o decreto também prevê a possibilidade da criação de novos livros de registro, caso se faça necessário; tal fato é de suma importância, dado o caráter dinâmico dos bens imateriais. Entretanto, é imprescindível compreender que o registro e o inventário, além de consolidar um bem 
intangível, proporcionam a formação de registros. Conforme salienta Fonseca,

[...] embora o registro não crie direitos de autor ou de propriedade intelectual para os detentores desse patrimônio, a documentação produzida pode servir de prova para a reivindicação de direitos. Pode, também, ser recurso importantíssimo para a validação de eventuais impactos sobre a dinâmica social dos grupos em questão, de intervenções feitas por agentes externos, ou mesmo subsidiar decisões da própria comunidade, sobretudo aquelas voltadas para a salvaguarda de seu patrimônio cultural (FONSECA, 2009, p. 29).

As manifestações culturais podem se perder se não houver quem a manifeste. Entretanto, o registro torna-se fonte de informação e referência cultural: 0 conceito de referência cultural delimita 0 entendimento que confere a especificidade do patrimônio cultural imaterial, uma vez que inaugura no cenário teórico a possibilidade de gestão e de conservação. Para tanto, é fundamental preservar as informações presentes nas manifestações e celebrações culturais. De acordo com Márcia Sant'Ana,

[...] o princípio do trabalho de salvaguarda do patrimônio cultural imaterial é compartilhar responsabilidades e informações. É desenvolver em estreito contato com os grupos sociais, que produzem, reproduzem e transmitem esse patrimônio os projetos de mapeamento, identificação, registro e fomento à valorização e à continuidade de bens culturais (SANT'ANA, 2003, p. 9).

No caso do Brasil, são ainda recentes para os estudiosos da área de preservação as experiências de reconhecimento do patrimônio imaterial. Nessa mesma direção, garantir o protagonismo e a autonomia dos detentores dos saberes e fazeres nos processos de preservação e difusão dos seus valores, das suas crenças, dos seus costumes, é uma questão que requer a mobilização comunitária durante a solicitação do Registro. É importante, portanto, manter a autonomia desses sujeitos durante o processo de salvaguarda, de forma a diminuir as distâncias entre as decisões tomadas pelos representantes do Estado e a realidade do universo dessas manifestações culturais.

O processo de autonomia, referido pelo IPHAN como um ponto fundamental para a salvaguarda dos bens constituídos como patrimônio imaterial, envolve, dentre outras questões, o desenvolvimento de recursos humanos e materiais para as melhorias das condições de sustentabilidade dos indivíduos e grupos envolvidos. A partir dessas discussões, o diálogo permanente dos agentes públicos com as comunidades envolvidas deve 
ocorrer durante os processos de registro e salvaguarda, em especial, o acompanhamento dos Planos de Salvaguarda.

Fato é que, segundo Oliveira (2004),

Deve-se ainda ampliar as discussões sobre os impactos da salvaguarda, atentando-se, principalmente, para as questões que possam surgir, tais como envolvimento das culturas populares com a divulgação e difusão dos seus saberes performáticos. Assim, deixamos em aberto alguns pontos que podem ser mais discutidos a partir da relação entre patrimônio imaterial e o mercado no Brasil: espetacularização das artes populares; o desenvolvimento de uma indústria cultural do "exótico"; a transformação de rituais sagrados em mercadoria e, enfim, o direito à propriedade intelectual dos portadores dessas manifestações (OLIVEIRA, 2004, p. 38).

A questão recai em como se registra uma cultura dinâmica. O estudo desenvolvido por Mário de Andrade, através das Missões de Estudos Folclóricos (MPF) pelo norte e nordeste do Brasil, no início do século $X X$, configura-se como um exemplo de primeira experiência de construção de fontes de informação ou fontes de referência. Os registros realizados pela MPF foram, no passado, um modelo do que se tornaria hoje o Registro de manifestações tradicionais do IPHAN, um princípio de documentação para o patrimônio imaterial. Daquele momento até o presente e, em termos atuais, a metodologia para se registrar um bem cultural em um dos quatro livros de registro, conforme indica o Decreto $\mathrm{n}^{0}$ 3.551 (BRASIL, 2000) envolve três fases:

a) levantamento do bem cultural apontado para proteção;

b) identificação e documentação do mesmo; e

c) o registro, que corresponde a um trabalho etnográfico capaz de definir se o bem cultural pode ou não ser inscrito em um dos quatro livros.

Como já referido, existem diferenças na metodologia de registro de um bem cultural material e de um imaterial. A literatura relativa à documentação, como ferramenta para a preservação da memória, inclui processos de catalogação e descrição, bem como cadastro, fotografia, fotogrametria e arqueologia. No próximo tópico, iremos descrever as características de registros utilizados pela Missão e sua classificação e guarda na Discoteca Pública Municipal de São Paulo, por Oneyda Alvarenga. 


\section{Mário de Andrade, Oneyda Alvarenga e a coleção da Missão de Estudos Folclóricos}

Mário de Andrade era escritor, músico de formação e participou de viagens promovidas pelos modernistas ao interior de São Paulo e Minas Gerais e ao norte e nordeste brasileiro, com o objetivo de conhecer a cultura brasileira. Iniciou um processo de coleta sistemática de documentação musical folclórica, com a intenção de realizar uma pesquisa etnográfica mais sistemática.

Durante as suas viagens, Mário de Andrade assistiu a ensaios e representações de danças dramáticas, enveredando pelo estudo da religiosidade e da música de feitiçaria nacional, do ritual do catimbó, no Rio Grande do Norte ao Carnaval no Recife. Além da pesquisa musical, Mário registrou, em seu diário de viagem, o interesse pela arquitetura e suas preocupações pelas condições de vida e trabalho do homem nordestino. Voltando a São Paulo, publicou suas notas de pesquisa e observações no recém-criado Diário Nacional, órgão do Partido Democrático, sob o título de "O Turista Aprendiz".

De 1929 até 1935, Mário de Andrade produziu uma série de trabalhos relativos à música nacional. Após este período, conscientizou-se de que a questão da nacionalização da música erudita brasileira não se restringia somente ao aspecto da pesquisa etnográfica, mas, pelo contrário, a inexistência de pesquisas era um reflexo de dificuldades em planos mais abrangentes, que envolviam questões político-ideológicas. Esta situação resultava da falta de apoio e incentivo financeiro do Estado, em razão do desinteresse geral da classe dominante pela música com temática popular nacional (CARLINI, 1994).

Como Diretor do Departamento de Cultura de São Paulo, propôs a participação do Estado em apoio e amparo à pesquisa científica do Folclore e da Música, colaborando para o incremento das iniciativas de caráter etnográfico, úteis em determinar a existência de acervos culturais para estudos e aproveitamento por compositores e artistas em geral. Entre as várias iniciativas promovidas pelo Departamento de Cultura de São Paulo, destacam-se aquelas direcionadas à música, à formação de pesquisadores especializados e à coleta etnográfica constante: criação da Discoteca Pública Municipal (DPM) (1935); curso de Dina Lévi-Strauss; e criação da Sociedade de Etnografia e Folclore (1936). A estas iniciativas, se somam, também, a viagem de Camargo Guarnieri a Salvador, Bahia (1937) e a Missão de Pesquisas Folclóricas (1938).

Vale ainda ressaltar que, com apenas um ano de existência, o Departamento de Cultura inaugura a DPM e, ao mesmo tempo, segundo Carlini (1994), Mário de Andrade já estabelecia correspondências junto à Câmara Cascudo, sobre a possibilidade de registrar fonograficamente as melodias folclóricas da região do nordeste brasileiro. Tal desejo foi expresso em um dos tópicos norteadores na criação da DPM, cujo objetivo seria "[...] manter um serviço de gravação especialmente destinado à música popular brasileira [...]". O acervo começou a ser realizado em 
1937, com os registros fonográficos efetuados em São Paulo, documentando manifestações populares encontradas nos Estados de São Paulo e em Minas Gerais, tais como congada e folia de reis, dentre entre outras, identificadas na cidade de Lambari e nos arredores da capital paulista (dança de Santa Cruz em Itaquaquecetuba).

A Missão de Pesquisas Folclóricas percorreu o Norte e o Nordeste do Brasil, registrando as manifestações culturais folclóricas, em especial de dança e música. Trouxe instrumentos musicais, objetos de culto, peças utilitárias, fotos, reproduções de desenhos, gravações musicais e filmes. Não só registraram em discos o folclore musical, como colheram informações complementares às gravações, permitindo uma visão em perspectiva do contexto socioeconômico das regiões visitadas.

A Missão visitou cinco cidades em Pernambuco, dezoito na Paraíba, duas no Piauí, uma no Ceará, uma no Maranhão e uma no Pará. Assistiram a representações de Bumba-meu-boi, Nau Catarineta, Cabocolinhos, Maracatu, Tambor-de-Criola, Tambor-de-Mina, Praiá, Aboios, Cocos, Catimbó, Sessões de Desafio, Xangôs, Cantigas de Roda, de Ninar, Cantos de Trabalho, Cantos Religiosos, Cateretê, Barca e muitos outros.

Através da experiência de Mário de Andrade com o trabalho exercido no Departamento de Cultura e das informações colhidas pela Missão de Pesquisas Folclóricas, foi possível consolidar um acervo e uma documentação que, no campo da Ciência da Informação, pode ser considerado como fonte de informação, compondo um excepcional conjunto de referência cultural. Nessa perspectiva, é possível inferir que as informações obtidas forneceram subsídios para a produção do Anteprojeto de lei que colaborou para lançar as bases do Serviço do Patrimônio Histórico e Artístico Nacional (SPHAN²).

Como anteriormente indicado, Oneyda Alvarenga era musicista e aluna de Mário de Andrade. Fez o curso de etnografia promovido pela Sociedade de Estudos Folclóricos e foi convidada para dirigir a Discoteca em 1935. Para além de seu cargo efetivo, Oneyda era uma estudiosa da música erudita e popular e, em 1937, ganhou o primeiro prêmio do Curso de Etnografia e Folclore da Prefeitura de São Paulo com o trabalho $O$ cateretê do sul de Minas Gerais, estudo desenvolvido no sul do estado de Minas Gerais, local de proveniência da autora.

À frente da DPM, tornou-se uma das principais referências em termos dos estudos de música folclórica no Brasil, dedicando grande parte de seu tempo ao Acervo da Missão de Pesquisas Folclóricas, com a catalogação dos objetos, registros sonoros, bem como as publicações das séries: Registro Sonoro do Folclore Musical Brasileiro e o Catálogo Ilustrado do Museu Folclórico. Durante o período em que foi diretora da Discoteca, Oneyda Alvarenga realizou diversas atividades no espaço musical, além de dedicar-se à publicação de obras especializadas, dentre

\footnotetext{
${ }^{2}$ Serviço do Patrimônio Histórico e Artístico Nacional (SPHAN) antecessor do Instituto do Patrimônio Histórico e Artístico Nacional (IPHAN).
} 
as quais se destaca sua participação na Enciclopédia da Música Brasileira, como consultora de folclore.

Em sua trajetória profissional, Oneyda Alvarenga refletiu sobre as atividades da DPM, seja no trabalho das coleções do acervo, nas publicações relativas às atividades da DPM, ou mesmo dialogando com áreas ainda incipientes no Brasil, no trato documental de acervos audiovisuais, voltados aos estudos do patrimônio cultural. Em sua origem, a DPM tinha como funções o registro da música erudita paulista, o registro do folclore musical brasileiro e o Arquivo da Palavra, este último abrangendo dois sub-ramos: o registro das vozes de homens ilustres do Brasil e os registros destinados diretamente aos estudos de fonética.

A primeira publicação oficial da DPM foi um relatório produzido por Oneyda Alvarenga na Revista do Arquivo Municipal v. 37, em 1942. Os relatórios publicados na Revista do Arquivo constituem fonte documental privilegiada e sua consulta revela dados preciosos para a descrição da organização da informação dada às coleções, estudos voltados ao planejamento e gestão da instituição, bem como ao seu público, incluindo uso, acesso, divulgação e comunicação de programas de formação (matéria de grande valia atualmente no que se refere aos estudos de educação patrimonial).

Em continuidade, será apresentada, no próximo tópico, a forma de organização da Discoteca, considerando que, desde a sua criação, a DPM continua prestando aos seus usuários acesso a um importante acervo.

\section{A Discoteca Pública Municipal}

Com o objetivo de apresentar as inovações apresentadas pela DPM em um contexto de preservação e de manutenção de acervos históricos, é necessário descrever os serviços oferecidos pela instituição ao seu público em 1942. O acervo da DPM compunha-se de coleções formadas por documentos registrados em papel, fotografia, películas cinematográficas, vinis, matrizes de acetato, artefatos e instrumentos musicais. Para além da guarda adequada de um acervo tão diverso, acrescenta-se a metodologia de organização da informação, que permitiu o acesso de sua documentação (inovadora para a época) e a efetiva comunicação com o seu público; enfim, de forma ininterrupta, com toda a sociedade brasileira e internacional desde sua inauguração, há mais de oitenta anos.

Tendo como ordenamento a origem, funcionalidade e descrição de suas coleções e serviços, apresentam-se algumas considerações sobre o conjunto do acervo histórico da Discoteca Oneyda Alvarenga, destacandose, a seguir, os serviços da DPM oferecidos em $1942^{3}$ :

1) Registros sonoros:

a)De folclore musical brasileiro;

b)De música erudita da Escola de São Paulo; e

\footnotetext{
${ }^{3}$ A descrição se apresenta como no original (ALVARENGA, 1942).
} 
c)Arquivo da palavra (vozes de homens ilustres do Brasil e gravações para estudos de fonética).

2)Museu etnográfico-folclórico, sobretudo destinado a instrumentos musicais populares brasileiros, complemento indispensável dos registros de folclore musical;

3)Arquivo de documentos musicais folclóricos grafados à mão;

4)Filmoteca em conexão com os registros de folclore musical brasileiro;

5-Coleções de discos para consultas públicas;

6-Biblioteca musical pública, de partituras e livros técnicos;

7-Arquivo de matrizes; e

8-Concertos públicos de discos.

Segundo o Relatório de 1942 da Diretora da DPM, a coleção de música erudita paulista era destinada ao registro das composições de músicos nascidos ou fixados em São Paulo. Constituía a série fonográfica música erudita (ME) e contava com seis discos. Os quatro primeiros foram gravados pelo coral paulistano, do Departamento de Cultura, sob a regência de Camargo Guarnieri; os discos desta Série ME são distribuídos pelas organizações culturais, discotecas e escolas de música, tanto nacionais como estrangeiras.

O Arquivo da Palavra (Série AP) compreendia, na data de publicação do relatório, 17 discos, dos quais 14 formavam uma coleção para estudo das pronúncias regionais do Brasil. Os trabalhos desta coleção contaram com a colaboração do filólogo brasileiro Agenor Nascimento e do poeta Manuel Bandeira. Para a sua execução, o País foi dividido em sete zonas fonéticas, representada cada uma por dois indivíduos - um culto e outro inculto - aos quais se fez ler um texto-padrão, contendo todos os fonemas da língua, cuja dicção era importante controlar. Os três discos restantes pertencem à coleção de vozes de homens ilustres do Brasil. Esta coleção, segundo Oneyda Alvarenga, era destinada a ser um documentário histórico; este acervo tal como a Série $M E$, teve os trabalhos paralisados por motivos diversos, porém a maior explicação se encontra na falta de apoio da gestão municipal aos estudos promovidos pela discoteca, principalmente após a saída de Mário de Andrade no Departamento de Cultura.

A Série registros de música popular brasileira (Série F) consta de 175 discos de acetato, de 12", $14^{\prime \prime}$ e 16", contendo 1.223 fonogramas. ${ }^{4}$ Estão representados nesta coleção os estados de São Paulo, Minas Gerais, Paraíba, Pernambuco, Maranhão e Pará. Os gêneros e tipos dos fonogramas registrados são os seguintes:

a)Cantos de trabalho (Carregadores de piano, carregadores de pedra, aboios);

\footnotetext{
4 "Fonograma é a fixação de uma obra em suporte material. Para que nos entendam de maneira mais simples é obra gravada" 1 Sinal gráfico que representa um som. 2 Inscrição do som, obtida por meio de aparelhos registradores, em fonética experimental. 3 Som gravado. Disco, placa, filme em que o som está gravado.
} 
b)Cantos de pedintes;

c)Dansas ${ }^{5}$-dramáticas (Barca, Bumba-Meu-Boi, Cabaçal, Cabocolinhos, Congada, Reisado, Reis do congo);

d)Cantos puros, não ligados a dansas [sic] (Acalanto, Cantiga, Carretilha, Chula, Décima, Desafio, Embolada, Gabinete, Galope, Improviso, Lundu, Martelo, Modinha, Morão, Mote-eglosa. Oitava, Quarteirão, Rojão, Seis-e-meio, Toada.);

e)Feitiçaria; (Babassûe, Catimbó, Pajelança, Tambor-deCrioulo, Tambor-de-Mina, Xangô);

f)Dansas rituais de núcleos indígenas civilizados (Praiá, Toré);

g)Dansas coletivas (cana-verde, cateretê, coco, taquaral, toré);

h)Dansas solistas (catimbó);

i)Dansas religiosas e costumes populares católicos (dansas de Santa cruz, dansa de São Gonçalo, folia de reis);

j)Jogos infantis (rodas); e

Música instrumental pura (solos de viola).

Esta coleção, quase sua totalidade compreende os discos gravados pela Missão de Pesquisas Folclóricas que a Discoteca manteve em trabalho pelo nordeste e norte brasileiros. Além dos importantíssimos discos registrados, a Missão colheu também a indispensável documentação fotográfica e cinematográfica, além de copioso material destinado ao Museu Etnográfico-folclórico: objetos diversos em conexão com o material musical pesquisado, admiráveis peças de escultura popular em madeira, etc. por falta de espaço na atual sede da discoteca, o Museu não está ainda, lamentavelmente, organizado e aberto ao público (ALVARENGA, 1942, p. 8).

Segundo o relatório, a filmoteca ligada ao material musical folclórico possui uma coleção de 28 filmes cinematográficos. Este acervo está catalogado em um fichário folclórico desenvolvido por Oneyda Alvarenga.

As coleções de discos para consultas públicas também são descritas por Oneyda Alvarenga, conforme a citação a seguir:

A discoteca possuem [SIC] atualmente 7.144 discos destinados a consultas públicas. Destes discos, somente as gravações de música popular brasileira (sejam ou não feitas pela discoteca) e as de folclore estrangeiro dependem, para serem consultadas, de autorização especial, por constituírem documentação científica (ALVARENGA, 1942, p. 19).

\footnotetext{
${ }^{5}$ A palavra "dansa" é assim grafada no texto original.
} 
As informações sobre os procedimentos de tratamento bibliotecário e arquivístico dado ao acervo e, também, dos métodos de conservação e armazenamento são descritas nos relatórios. A seguir, indicamos as orientações específicas correspondentes às atividades da DPM, conforme Oneyda Alvarenga:

[...] Armazenamento: "As coleções são guardadas em armários com capacidade para 2.100 discos, dotadas de 60 divisões verticais numeradas de 1 a 10, podendo conter cada uma 35 discos".

Notação: A numeração dos armários é seguida 91 , 92, etc e as da divisão de cada um é sempre a mesma: de 1 a 60. Os discos recebem, em cada armário, a numeração de 1 a 2.000. Não foi adotada a numeração seguida do total das coleções para evitar no fichário números de chamada muito grandes. 0 número de chamada do disco é dado pelo número do armário, da divisão e pelo seu número de ordem. Temos, por exemplo, a ficha "nuages" de Debussy com o seguinte número de chamada:

1,1,1- o que quer dizer; armário no 1 , disco 1.

Acondicionamento: Para darem entrada nos armários, os discos são colocados em envelopes especiais de diversas cores, trazendo nas suas faces externas todas as referências necessárias. O modelo destes envelopes é uma adaptação, com pequenas modificações, do tipo usado pela Discoteca do Serviço Oficial de Difusão Rádio-elétrica de Montevidéu (Uruguai); assim é que adotamos várias cores para melhor separação das composições ou séries, mudamos a posição do número de chamada para o alto, escrito nas duas faces, a fim de se achar o disco sem necessidade de puxá-lo da divisão para a leitura do número; entre as características foram acrescentadas as de "conjunto de câmara" e "intérpretes", está em previsão dos casos em que não se possam incluir os intérpretes nas rubricas existentes a eles destinada. (...)

Catalogação: O fichário de discos, - o processo de catalogação dos discos obedece a um catálogo sistemático, com seis seções: Autores; Formas; Países, Séculos, Executantes e Títulos (ALVARENGA, 1945, p. 20).

Oneyda Alvarenga foi aluna da Sociedade de Estudos Folclóricos (SEF) e em entrevista realizada com a atual diretora da Discoteca ${ }^{6}$, foi informado que em seu arquivo pessoal existe um acervo de livros de biblioteconomia, organização de acervos, etnologia, folclore, história da

\footnotetext{
${ }^{6}$ Entrevista concedida por Jéssica Barreto, em 25 de setembro de 2013.
} 
música dentre outros assuntos. Estes livros estão em português e, também, em língua estrangeira, o que nos leva a inferir que tal qual ao mestre, a discípula era uma pessoa estudiosa e uma pesquisadora sistemática dos assuntos de seu interesse.

A organização da DPM revela que sua construção só foi possível através de um trabalho minucioso, a partir de importantes estudos e investigação, levando à produção de instrumentos eficientes, como os diversos catálogos e fichas de coleta de dados, gerando um sistema de recuperação de informações adequado e inovador. O trabalho, então realizado, foi posteriormente recebido com surpresa em outras instituições, havendo, inclusive, pedidos de exemplares, como as fichas catalográficas utilizadas para serem adaptadas em acervos etnográficos e de materiais em meios magnéticos. Além do interesse sobre as matrizes produzidas pela Missão de Pesquisas Folclóricas. Há, nas correspondências entre Mário de Andrade e Oneyda Alvarenga, trechos que evidenciam esta situação, ou seja, o interesse em obter as matrizes, tanto pelo Museu Nacional (Brasil) quanto na Library of Congress - LC (Estados Unidos da América). A formulação abaixo reitera a existência do interesse no trabalho da DPM,

Em 30 de maio de 1939, Oneyda Alvarenga já menciona o interesse de Henry MacGeorge, da Library of Congress, no intercâmbio de material folclórico da Discoteca Municipal [...] em carta a Mário de Andrade o texto menciona uma conferência de Harold Spivacke, chefe da divisão de música da biblioteca do congresso, em Washington, que Oneyda ouviu com toda atenção (CAROZZE, 2012, p.170).

Após estudar o áudio da conferência, Oneyda questiona posteriormente o método que os profissionais da LC manuseavam e produziam as matrizes dos discos de acetato. Ela, então, inicia uma troca de correspondências com o responsável técnico norte-americano e, com surpresa, recebe um pedido para que se faça intercâmbio de material de gravação, além das fichas de catalogação. Mário de Andrade recomenda cautela, porque, afinal, tratava-se de disponibilizar material inédito brasileiro, de pesquisa. Mas, em contrapartida, a DPM receberia material virgem para a produção de novas matrizes, além do reconhecimento internacional do trabalho da Discoteca. Conforme Carozze,

Se os interesses de Oneyda Alvarenga nos conhecimentos e no material de Spivacke eram de ordem técnica, pelo menos de início, os de Mário se focalizavam diretamente no conteúdo. "Quanto ao que você escolher, pergunte desde logo, o que ele tem de negros da África, de Portugal; de Cuba; de ameríndios; e de negros africanos (grifos do autor) de origem, já nos Estados Unidos" e triunfante, Mário de Andrade acrescenta: "e o fato dele não ter fotos, filmes, instrumentos e toda documentação musical anexa ao documento musical, prova 
que nossa discoteca foi mais cientificamente concebida que a dele... viva nós, minha cara (CAROZZE, 2012, p. 171).

Também podemos verificar que o armazenamento dos discos foi eficiente, haja vista que, mesmo com diversas movimentações da coleção em decorrência das constantes mudanças de sede, pouco se perdeu, estando os discos, hoje, em perfeito estado de conservação. Infelizmente, não se tem no relatório dados mais precisos quanto aos procedimentos de conservação para além da citação feita.

No Relatório de 1942, estão descritos os serviços e as normas orientadoras de consulta para o público, bem como as estatísticas de uso da coleção. A DPM teve, em seus primeiros anos de vida, dificuldades para manter o serviço de consultas, devendo-se tal fato à espera pela compra dos equipamentos de audição (que eram fundamentais para a formação da estrutura específica de uso de materiais de áudio) e a compra de matrizes, ou seja, dos discos. Todo o equipamento adquirido era importado da Europa e dos Estados Unidos, o que gerava uma situação na qual havia a demora do recebimento do equipamento. Conforme Sampietri (2009),

[...] outro motivo para a demora no início dessa atividade foi o problema de falta de pessoal especializado. Tal atividade demandava pessoal especializado, principalmente para a formação do fichário de consultas. Vale lembrar que esse tipo de demanda era suprida com a presença de um profissional de biblioteconomia e esse curso, ainda em fase incipiente no Brasil, passou a ser oferecido pelo próprio Departamento de Cultura a fim de formar mão-de-obra especializada para a rede de bibliotecas que o departamento começava a criar, organizando as bibliotecas já existentes, criando novas bibliotecas e novos projetos, como as bibliotecas populares e 0 ônibus biblioteca. Paulo Duarte, em Mário de Andrade por ele mesmo, ainda lembra que o curso de biblioteconomia oferecido pelo Departamento de Cultura, em sua primeira turma, já contava com duzentos alunos (SAMPIETRI, 2009, p. 78).

A citação acima apresenta a criação do primeiro curso de biblioteconomia em São Paulo, segundo Russo (1966):

O primeiro curso regular de Biblioteconomia em São Paulo (e segundo no Brasil), de fato, surgiu em 1936, promovido pelo Departamento de Cultura da Prefeitura Municipal de São Paulo; e que teve como professores e coordenadores a bibliotecária Adelpha Figueiredo e outro renomado bibliotecário, Rubens Borba de Moraes. A Biblioteca Municipal de São Paulo serviu de laboratório prático para muitos futuros 
bibliotecários. Apesar dos altos números de matrículas, o curso teve a subvenção cancelada pela Prefeitura em 1939, pelo então novo prefeito Prestes Maia; sendo extinto neste ano. Porém, o curso ressurge em 1940, desta vez, incorporado à Escola de Sociologia e Política de São Paulo (atual Fundação Escola de Sociologia e Política de São Paulo), que existe até hoje. (RUSSO, 1966 apud ALMEIDA, 2012, p. 46)

Desde o início das atividades, vimos uma preocupação com o mapeamento do público consulente da discoteca e de oferecer acesso a toda a cidade, mediante a inclusão das atividades da DPM em outras instituições do Departamento de Cultura. Oneyda Alvarenga criou uma tabela de informação sobre os consulentes, com itens pré-estabelecidos, que ajudassem a dar uma ideia do perfil dos seus usuários. Esta informação nos leva a inferir o papel de vanguarda de Oneyda Alvarenga em trabalhos específicos de unidades de informação. Na realidade, os Estudos de Usuários e os estudos de referência que originaram os serviços de disseminação seletiva de informação são metodologias e abordagens de pesquisa, comuns na literatura na Ciência da Informação a partir da década de 1970. A implantação de um serviço de atendimento especializado na Discoteca à época, leva-nos a refletir que a diretora da DPM, construiu um estudo com base nos gostos, nacionalidade e frequência de uso de seus consulentes, proporcionando uma metodologia eficiente para o serviço de atendimento e de consultas.

A leitura do Relatório de 1942 possibilita verificar como foi introduzido o serviço de atendimento na discoteca; a princípio, o serviço de consultas registrava informações apenas das obras consultadas. Com o objetivo de planejar as atividades de atendimento e a marcação de consultas, que demandavam pesquisa no acervo, a partir de junho de 1939, a DPM resolveu cadastrar os consulentes. Além de uma listagem, foi introduzido um campo para obter dados sobre a nacionalidade, haja vista ser este dado importante, pois São Paulo recebeu um número enorme de imigrantes europeus no período entre guerras. Estes imigrantes consultavam o acervo da discoteca, pois, ao ouvir as músicas de compositores europeus, sentiam-se confortados e estabeleciam uma rotina de uso tanto para fruição e lazer quanto para apoio às aulas de música, como material didático.

De forma geral e em termos do que se apreendeu em relação à DPM, torna-se patente que eram incipientes os trabalhos de biblioteconomia na época e de pessoal especializado à disposição para os trabalhos na Discoteca. Entretanto, é notável encontrar princípios de uma organização eficiente expressos nos serviços prestados, hoje caracterizados como serviços especializados de informação, bem como nas concepções de atendimento ao usuário em consultas individuais ou mesmo em grupos.

Para as consultas do acervo de áudio, os consulentes poderiam utilizar cabines de audição. Segundo Sampietri (2009, p. 81), "as cabines 
foram confeccionadas especialmente para a discoteca. Eram de madeira e desmontáveis, o que facilitava seu transporte. Infelizmente não possuímos detalhes do fabricante". Com o passar dos anos, a DPM recebeu novas cabines com maior capacidade de consulentes; as críticas em torno do pequeno espaço de consultas e das longas filas de consulentes estão presentes em artigos publicados na Folha da Noite em 1940. Segundo Sampietri,

é preciso entender que as limitações geravam uma série de regras que limitavam o acesso do público ao serviço de audição, gerando uma série de inconvenientes. Essas regras foram criadas em função dos horários exíguos em que a discoteca funcionava e o já visto número de cabines (SAMPIETRI, p. 84, 2009).

Novamente, o relatório de 1942 surge como relevante fonte documental, na medida em que estão disponíveis as estatísticas de uso e as conclusões escritas pela própria diretora que indicam as orientações que balizaram as diretrizes para a construção da instituição, a manutenção da memória e sua efetiva utilização pelos cidadãos da cidade.

Para Sampietri (2009), o fato de Oneyda Alvarenga ter-se preocupado com a questão de organizar e acondicionar o material, de maneira a poder recuperar informações por meio de diversas entradas de busca, facilitando o trabalho do consulente, a fez estudar minuciosamente as formas de recuperação de informações existentes na época, tornando a Discoteca Municipal inovadora em seu tempo. A citação abaixo comprova tal afirmação:

Mais uma vez, o Relatório de 1942, que abarca as impressões da chefe da discoteca em relação ao serviço de consultas no período de 1936 a 1942, dá as pistas de como essa organização funcionou e tomou corpo. A chefe da discoteca organizou fichários com diferentes entradas. Cada música encerrada na discoteca possuía de 10 a 16 entradas, ou seja, o consulente chegava com informações mínimas a respeito de uma determinada música que desejava ouvir e através dessas informações era possível localizar o objeto de desejo rapidamente. Vale notar que tal tema toma boa parte do relatório, o que demonstra a importância atribuída a esse serviço de confecção de fichas bibliográficas para disco. São 22 páginas das 98 dedicadas à exposição das opções da discoteca em relação à confecção científica de fichários catalográficos e à sistematização de dados (SAMPIETRI, 1999, p. 87).

Entretanto, uma coleção organizada para ecoar no vazio não condiz com os princípios de uma instituição moderna. As inovações apresentadas 
nos sistemas de recuperação de informação da DPM apresentam uma série imensa de possibilidades de busca de informações; porém, a facilidade de acesso promovida pelas atividades de empréstimo da biblioteca de partituras ia ao encontro das outras atividades oferecidas pela DPM. Os concertos comentados, audições em grupo ou individuais, uma coleção de referência de qualidade com títulos variados, dentre outros, permitia um acesso fácil e disponível para o usuário, seja este especializado ou mesmo um leigo. Oneyda Alvarenga, no relatório de 1942, coloca que "mesmo que um consulente possua poucas informações sobre o que pretende ouvir, este catálogo minucioso permite-lhe encontrar facilmente o que procura. Por outro lado, as divisões ajudam os estudos sistemáticos." (ALVARENGA, 1942, p. 87).

A DPM continua, até hoje, ofertando aos seus usuários consulta ao material histórico. É importante destacar que a apresentação temporal dos serviços presentes neste artigo são relativos ao período de sua criação, em especial aqueles descritos em seu relatório de 1942. Naquele momento, os dados referentes às consultas variavam, mas mantinham-se constantes em vários aspectos, evidenciando a formação de um grupo seleto e profissional. Por outro lado, o número crescente de consulentes estudantes traduz, na análise de Oneyda Alvarenga, a verdadeira função da DPM, desde a sua fundação. A preocupação estava no fato de que, no início, a DPM deveria atrair um público maior de pessoas ligadas à música; afinal de contas, o objetivo da instituição não era para servir de um espaço apenas para entretenimento ou simples passatempo, pretendia-se atuar nas áreas de pesquisa e formação musical.

A discoteca deveria atrair um público maior de pessoas ligadas à música, entretanto, o contínuo aumento de consulentes leigos e estudantes fizeram que Oneyda Alvarenga mudasse de opinião. Apesar da decepção em relação aos músicos, foi na frequência e na dominância de estudantes que a musicista depositou suas esperanças em relação ao papel social da discoteca. Se não era possível atrair um bom número de músicos formados para os acervos da discoteca, pelo menos seria possível atingir um extrato maleável e pronto para o aprendizado. O projeto se justificaria no futuro e compensaria em longo prazo. Em termos de tal ideário a realidade da DPM hoje parece confirmá-lo, pois, continua a disponibilizar aos usuários consulta ao seu material histórico.

Atualmente, a Discoteca Oneyda Alvarenga faz parte do Centro Cultural São Paulo e possui em seu acervo sonoro aproximadamente 45.000 discos de 78 rpm, 30.000 discos de 33 rpm e 2.500 CDs. Parte das coleções digitalizadas está disponível para audição no site da Web Rádio CCSP (Centro Cultural São Paulo). Além de cerca de 62 mil partituras de música erudita, popular, nacional e estrangeira; 10 mil livros de música; e 400 títulos de revistas e hemeroteca musical (recortes de jornal) com 1.700 assuntos, dentre outras coleções. A Discoteca Oneyda Alvarenga, desde a sua origem, continua a informar e a disseminar o que havia criado e sua permanência ao longo do tempo reflete a sua maior riqueza e seu caráter de preciosidade para a pesquisa musical e etnográfica. 
Em 1982, depois de passar por várias sedes, a Discoteca foi transferida para o Centro Cultural São Paulo e, a partir de 1987, passou a receber o nome de Oneyda Alvarenga, em homenagem a sua primeira diretora, que exerceu o cargo até 1968. Hoje, a Discoteca Oneyda Alvarenga está organizada em três setores e as consultas permanecem constantes.

\section{Conclusão}

Como preciosa fonte documental, o acervo da Discoteca Oneyda Alvarenga permite aos pesquisadores e ao público obter informações importantes sobre a organização da Discoteca (seu regimento interno e relatórios), sendo uma das primeiras instituições brasileiras voltadas exclusivamente ao estudo da cultura imaterial, por manter em seu acervo registros audiovisuais e sonoros de rituais, costumes e músicas da cultura brasileira, correspondente ao princípio do século XX.

Em seus registros históricos, é possível verificar suas atividades, que hoje denominamos de difusão cultural, com detalhes de pré-produção, produção e dos impactos sobre o seu público na época. A indicação de que havia registrado esses dados e publicado as estatísticas de frequência de público constitui fonte de informação privilegiada proporcionando uma fonte de informação a outras áreas afins da memória coletiva e da preservação patrimonial.

Porém, diversas questões se colocam acerca da importância da proteção ao patrimônio cultural e a regulamentação das ações de preservação de bens culturais em nível mundial. No contexto atual, em que cresce concomitantemente à preocupação com o documento e com a informação nele contida, o que impulsiona grande parte das discussões e propostas para ações e políticas de proteção do patrimônio cultural na sociedade, podemos considerar que a Discoteca Oneyda Alvarenga e sua permanência no contexto atual, nos permitem considerá-la como um modelo adequado ao trabalho dedicado a este tipo de registro, bem como na gestão de instituições culturais que possuem como objetivos a manutenção e a guarda de registros culturais etnográficos em suporte audiovisual.

Nesse sentido, é urgente manter e disponibilizar a documentação do bem cultural imaterial para que o mesmo possa servir de referência cultural para a salvaguarda do conhecimento e posterior consulta. Esta é a grande inovação no trabalho elaborado por Oneyda Alvarenga, na Discoteca Municipal, no início do século passado.

Assim, este trabalho criado por Oneyda Alvarenga, permite ao cidadão de hoje conhecer como eram as músicas, os rituais e demais manifestações culturais da época. Além disso, e mais significativamente, permite, conforme determina no presente a função do Registro e do Inventário para o trato do patrimônio imaterial, oferecer à sociedade informações que possam contribuir para a valorização das memórias e histórias locais. Conforme Lévi-Strauss, 
[...] patrimônio imaterial, nasce, vive e morre. Intimamente associado à vida cotidiana das pessoas, não se poderia congelá-lo, em perenizá-lo por decreto. Gostos, necessidades, modos de vida, valores e representações sempre evoluíram e continuarão a fazê-lo e, se uma comunidade abandona uma prática social, não há como se opor. O que pode ser feito e o decreto atende a isto, é, por um lado, inventariar, estudar e conservar e, por outro, oferecer reconhecimento social aos detentores desse patrimônio para que tenham reconhecida as novas gerações que, por sua vez, terão tomado consciência de seu valor (LÉVI-STRAUSS, 2001, p. 27).

Entretanto, pergunta-se: estão os profissionais que lidam diretamente com a manutenção de espaços de memória como bibliotecas, arquivos e museus cientes das relações estabelecidas junto à sociedade que mantém e legitima as instituições em que atuam preparados para lidar com as demandas informacionais necessárias? Estão habituados a lidar com a variedade e as necessidades desses tipos de artefatos ou de seus registros? Quais são as principais dificuldades enfrentadas? Quais são as principais referências voltadas às possibilidades informativas desses acervos?

Em face destas indagações, cabe à Ciência da Informação, enquanto campo do saber, estar apta a exercer, na área do patrimônio cultural, ações efetivas, seja por meio de melhor qualificação de seus formandos e profissionais, seja como espaço de reflexão das questões mais amplas relativas ao acesso e à manutenção de acervos e coleções específicas. Vale acrescentar, ainda, a necessidade e importância de trabalhos e pesquisas de cunho técnico, específicas no tratamento e nas metodologias e atividades informativas básicas de atendimento ao usuário, consulente, visitante e cidadão. Portanto, conhecer trabalhos produzidos em épocas passadas permite não só contar, no presente, com um conjunto de experiências a serem analisadas e tomadas como referência para novos empreendimentos, mas, fundamentalmente, como instrumento para a ação.

\section{Referências}

ABREU, R. M. R. M. Quando as pessoas se transformam em patrimônio cultural. In: ABREU, R. M. R. M.; CHAGAS, M. (Org.). Memória e patrimônio: ensaios contemporâneos. 2. ed. Rio de Janeiro: Lamparina, 2009. v. 1, p. 83-97.

ALVARENGA, O. A Discoteca Pública Municipal. Revista do Arquivo Municipal, v. LXXVII, 1942. p. 7-46.

ALMEIDA, N. B. F. Biblioteconomia no Brasil análise dos fatos históricos da criação e do desenvolvimento do ensino. 2012. 160f. Dissertação 
(Mestrado em Ciência da Informação) - Faculdade de Ciência da Informação da Universidade de Brasília, Brasília - DF, 2012.

ANDRADE, M.; ALVARENGA, O. Cartas. São Paulo: Duas cidades. 1983.

ANDRADE, M. Anteprojeto para a criação do Serviço do Patrimônio Artístico Nacional. Revista do Patrimônio Histórico e Artístico Nacional, Mário de Andrade, n. 30, 2002.

ANDRADE, M. O turista aprendiz. Belo Horizonte: Itatiaia, 2002.

BRASIL. Presidência da República. Decreto-Lei n. 0 25, de 30 de novembro de 1937. Organiza a Proteção do Patrimônio Histórico e Artístico Nacional. DOU, 6 dez. 1937. Disponível em: <www.iphan.gov.br>. Acesso em: 9 out. 2009.

CARLINI, Á. Cante lá que gravam cá: Mário de Andrade e a missão de pesquisas folclóricas de 1983. 1994. 190f. Dissertação (Mestrado em História) - Faculdade de Filosofia, Letras e Ciências Humanas da universidade de São Paulo, São Paulo, 1994.

BRASIL. Presidência da República. Decreto n 3.551, de 4 de agosto de 2000. Institui o Registro de Bens Culturais de Natureza Imaterial que constituem patrimônio cultural brasileiro, cria o Programa Nacional do Patrimônio Imaterial e dá outras providências. Disponível em: $<$ http://www.planalto.gov.br/ccivil_03/decreto/D3551.htm>. Acesso em: 6 ago. 2004.

DEPARTAMENTO DE PATRIMÔNIO IMATERIAL. Instituto Do Patrimônio Histórico E Artístico Nacional (IPHAN). Os sambas, as rodas, os bumbas, os meus e os bois: a trajetória da salvaguarda do patrimônio cultural imaterial no Brasil. Brasília: IPHAN, 2006.

DUARTE, P. Mário de Andrade por ele mesmo. 2. ed. São Paulo: Hucitec; PMSP, 1985.

FENELON, D. R. Políticas culturais e patrimônio histórico. In: CONGRESSO INTERNACIONAL PATRIMÔNIO HISTÓRICO E CIDADANIA, n. 2, 1991, São Paulo. O direito à memória: patrimônio histórico e cidadania. São Paulo: $\mathrm{DPH}, 1992$. p. 29-33.

INSTITUTO NACIONAL DO FOLCLORE. Mário de Andrade e a sociedade de etnografia e folclore. São Paulo: FUNARTE / SMC-SP, 1983.

FONSECA, M. C. L. O patrimônio em processo: trajetória da política de preservação no Brasil. Rio de Janeiro: UFRJ/ IPHAN, 1997.

FONSECA, M. C. L. Para além da pedra e cal: por uma concepção ampla de patrimônio cultural. In: ABREU, R; CHAGAS, M. (Orgs.). Memória e patrimônio: ensaios contemporâneos. Rio de Janeiro: DP\&A, 2003. p. 5979.

CARMO, R. A. M. L. do. A política federal de salvaguarda do patrimônio cultural imaterial. Disponível em: <http://culturadigital.br/politicaculturalcasaderuibarbosa/files/2010/09/35 
-RAIANA-ALVES-MACIEL-LEAL-DO-CARMO.1.pdf>. Acesso em: 14 out. 2012.

CAROZZE, V. M. A menina boba e a discoteca. 2012. 370f. Dissertação (Mestrado em Culturas e Identidades Brasileiras) - Instituto de Estudos Brasileiros, Universidade de São Paulo, São Paulo, 2012. Disponível em: <http://www.teses.usp.br/teses/disponiveis/31/31131/tde-04122012185949/>. Acesso em: 8 out. 2013.

FRANÇA, J. L. et al. Manual para normalização de publicações técnicocientíficas. 6. ed. rev. ampl. Belo Horizonte: UFMG, 2003.

INSTITUTO DO PATRIMÔNIO HISTÓRICO E ARTÍSTICO NACIONAL (IPHAN). A trajetória da salvaguarda do patrimônio imaterial do Brasil. Disponível em <http://portal.iphan.gov.br/portal/montarDetalheConteudo.do?id=13236\& sigla $=$ Instituci onal\&retorno=detalheInstitucional $>$. Acesso em: 14 out. 2006.

LÉVI-STRAUSS, L. Patrimônio Imaterial e diversidade cultural: o novo decreto para a proteção dos bens imateriais. Revista Tempo Brasileiro, Rio de janeiro, n. 147, p. 23-28, out.-dez. 2001.

LE COADIC, Y-F. A ciência da Informação. Brasília: Briquet de Lemos, 1996.

LE GOFF, J. Einaudi 1: memória/ história. Portugal: Imp. Nacional Casa da Moeda, 1982. p. 95-106.

LONDRES, M. C. Construção das políticas internacionais de referência para a salvaguarda do patrimônio cultural imaterial. Curso a distância, Patrimônio imaterial: política e instrumentos de identificação, documentação e salvaguarda. UNESCO, 2008. (Não publicado).

LONDRES, M. C. Informação e patrimônio imaterial. In: SILVA, H. de C. S.; BARROS, M. H.. T. C. (Org.). Ciência da Informação: múltiplos diálogos. Marília: Oficina Universitária Unesp, 2009. p. 23-30.

MOYA, F. N. A Discoteca Pública Municipal de São Paulo: um projeto modernista para a música nacional. 2010. 144f. Dissertação (Mestrado em História) - Faculdade de Ciências e Letras de Assis (UNESP), Universidade Estadual Paulista, Assis, 2010.

MICELI, S. O processo de 'construção institucional' na área da cultura federal (anos 70). In: MICELI, S. (Org.). Estado e cultura no Brasil. São Paulo: DIFEL, 1984. p. 53-94.

NOGUeIRA, A. G. R. Por um inventário dos sentidos: Mário de Andrade e a concepção de patrimônio e inventário. São Paulo: Editora Hucitec; Fapesp, 2005.

NOGUEIRA, A. G. R. Inventário e patrimônio cultural no Brasil. História, São Paulo, v. 26, n. 2, p. 257-268, 2007. 
OLIVEIRA, A. G de. A diversidade cultural como categoria organizadora de políticas públicas. In: TEIXEIRA, J. G. L. C. (Org.). Patrimônio imaterial, performance e (re)tradicionalização. Brasília: ICS-UnB, 2004. p. 37-42.

POSSAMAI, Z. R. O patrimônio em construção e o conhecimento histórico. Revista Ciência e letras, Porto Alegre, v. 25, n. 27, p. 189-203, jan./jun. 2000.

REIS, A. S.; CABRAL, A. M. (Orgs.). Informação, cultura e sociedade: interlocuções e perspectivas. Belo Horizonte: Novatus, 2007. p. 29-48.

REVISTA DO PATRIMÔNIO HISTÓRICO E ARTÍSTICO NACIONAL. Mário de Andrade. n. 30, 2002.

RUSSO, L. G. M. A biblioteconomia brasileira: 1915 - 1965. Rio de Janeiro: INL, 1966.

SAMPIETRI, C. E. A Discoteca Pública Municipal de São Paulo: (19351945). 2009. 208f. Dissertação (Mestrado em História Social) - Faculdade de Filosofia, Letras e Ciências Humanas da Universidade de São Paulo, São Paulo, 2009.

SANT.ANNA, M. A face imaterial do patrimônio cultural: os novos instrumentos de reconhecimento e valorização. In: ABREU, R. M. R. M.; CHAGAS, M. (Orgs.). Memória e patrimônio: ensaios contemporâneos. 2. ed. Rio de Janeiro: Lamparina, 2009. Pp.49-58.

SARACEVIC, T. Ciência da Informação: origem, evolução e relações. Perspectivas em Ciência da Informação, Belo Horizonte, v. 1, n. 1, p. 4161, jan./jun. 1996.

TONI, F. C. A missão de pesquisas folclóricas do Departamento de cultura de São Paulo. São Paulo: Centro Cultural São Paulo; Secretaria Municipal de Cultura, 1984.

TONI, F. C. Missão: pesquisas folclóricas. REVISTA USP, São Paulo, n. 77, p. 24-33, mar./maio 2008.

UNESCO. Políticas culturais para o desenvolvimento: uma base de dados para a cultura. Brasília, DF: UNESCO, 2003.

UNESCO. Patrimônio imaterial no Brasil: legislação e políticas estaduais. Brasília: UNESCO; Educarte, 2008. Disponível em: <http://unesdoc.unesco.org/images/0018/001808/180884POR.pdf>.

Acesso em: 22 set. 2009. 